\title{
Analysis of Genomic DNA Methylation Levels in Human Placenta using Liquid Chromatography-Electrospray Ionization Tandem Mass Spectrometry
}

\author{
Sulistyo Emantoko Dwi Putra ${ }^{a}$ Corinna Neuber ${ }^{b}$ Christoph Reichetzeder ${ }^{a}$ \\ Berthold Hocher ${ }^{\mathrm{a}, \mathrm{c}}$ Burkhard Kleuser ${ }^{\mathrm{b}, \mathrm{c}}$
}

anstitute of Nutritional Science, Department of Experimental Nutritional Medicine, University of Potsdam, 'Institute of Nutritional Science, Department of Toxicology, University of Potsdam, PotsdamRehbrücke, Germany; 'equally contributing senior authors

\author{
Key Words \\ Pregnancy • Placenta • Methylation • Global • LC-MS/MS • Fetal programming • Clinical
}

\begin{abstract}
Background: DNA-methylation is a common epigenetic tool which plays a crucial role in gene regulation and is essential for cell differentiation and embryonic development. The placenta is an important organ where gene activity can be regulated by epigenetic DNA modifications, including DNA methylation. This is of interest as, the placenta is the interface between the fetus and its environment, the mother. Exposure to environmental toxins and nutrition during pregnancy may alter DNA methylation of the placenta and subsequently placental function and as a result the phenotype of the offspring. The aim of this study was to develop a reliable method to quantify DNA methylation in large clinical studies. This will be a tool to analyze the degree of DNA methylation in the human placenta in relationship to clinical readouts. Methods: Liquid chromatography-electrospray ionization/multi-stage mass spectrometry (LC-ESI/MS/MS) technique was used for the quantification of the $5 \mathrm{dmC} /$ dG ratio in placentas from 248 healthy pregnancies. We were able to demonstrate that this method is a reliable and stable way to determine global placental DNA methylation in large clinical trials. Results/Conclusion: The degree of placental DNA methylation seen in our pilot study varies substantially from $2 \%$ to $5 \%$. The clinical implications of this variation need to be demonstrated in adequately powered large studies.
\end{abstract}


Putra et al.: DNA Methylation Levels in Human Placenta

\section{Introduction}

The 'fetal origin' hypothesis proposes that adulthood hypertension, insulin resistance, dyslipidaemia and non-insulin-dependent diabetes, which are connected to markedly increased rates of cardiovascular disease in adult life, originate through adaptation of the fetus to an early intrauterine environment. It has been suggested that not only maternal nutrition but also maternal exposure to toxins like alcohol, nicotine but also toxins in water and food in early life cause functional and structural changes of the newborn resulting in adulthood hypertension, insulin resistance and dyslipidaemia [1]. Epigenetics serves as an important mechanism capable of regulating gene transcription and linking events early in life to adult morbidity. It is comprised by heritable changes in chromatin that alter gene expression without altering the DNA sequence [2-4]. Throughout gestation, the placenta plays a crucial role in controlling growth and development of the fetus. The placenta acts as an interface between the growing child and its environment, the mother. Nutritions, toxins and any environmental challenge of the pregnant mother act on the newborn via the placenta. Moreover, the placenta also produces specific hormones affecting both the mother and the growing child [5]. The placenta itself develops within several weeks from pluripotent cells to a highly differentiated organ. Its epigenome is critical for normal placental function [6], and plays an important role in programming events occurring during early phases of pregnancy. After fertilisation, both paternal and maternal genomes undergo demethylation [7]. Establishment of correct epigenetic patterns in the trophoblast is crucial for the formation of the fetal side of the placenta and epigenetic factors play an important role in placental maturation and development [8]. It is known that placental function can be influenced by the environment throughout pregnancy, thereby impacting on the appropriate genetic programming needed to allow for proper fetal growth [4]. Exposure to environmental toxins and nutrition during pregnancy may alter DNA methylation of the placenta and subsequently placental function [9-11]. As a result this, can also trigger epigenetic changes in the offspring, ultimately altering its phenotype [12]. It is believed that these epigenetic alterations lead to a stable reset of key endocrine and structural properties of the offspring, thus potentially causing disease in later life [13].

DNA methylation, which is the best understood DNA epigenetic modification, may provide an attractive mechanism linking environmental cues to placental pathology, with consequences for fetal growth and adult life [4]. Methylation in vertebrate DNA is, in general, restricted to cytosine (C) nucleotides in the sequence Cytosin-Guanin (annotated CpG). The overall frequency of $\mathrm{CpG}$ dinucleotides in the vertebrate genome is low, but there are small stretches of DNA that are characterized by having CpG dinucleotides, extending for hundreds of bases, termed CpG islands [14-16]. The methylation status of cytosine residues, within CpG dinucleotides and in the context of CpG islands, provides an important mechanism for controlling gene expression activity $[14,16,17]$. Changes in the methylation status (hyper- or hypomethylation) have been associated with various health conditions including malignancies [18]. Besides affecting gene specific methylation patterns [11, 12], recent studies demonstrated that environmental cues impact on the global methylation status of the placenta $[9-11,19]$. To shed more light on the consequences of this phenomenon, it is important to analyze the degree of placental DNA methylation in large clinical studies in relationship to clinical readouts. For doing so, the establishment of a suitable method to quantify placental DNA methylation is thus urgently needed. In the current study, we developed a reliable method to quantify DNA methylation in the human placenta based on previous work by Song and colleagues [20].

\section{Materials and Methods}

Clinical study

We used 248 placenta samples collected as part of the Berlin Birth Cohort study [21-23]. The study was approved by the local ethics committee. Biometric data of the newborn were measured during the routine 
postnatal examination. Gestational age at delivery was based on last menstrual period, anamnestically assessed during the first pregnancy examination. The following data of the newborn were added to the database: birth weight, birth length, head circumference, ponderal index, child sex, Apgar score 5 minutes postnatally, Apgar score 10 minutes postnatally and umbilical blood pH levels. Fetal blood was collected from the umbilical cord. Midwives collected maternal blood from a cubital vein in the delivery room or on the ward. Placenta was collected and frozen at $-20^{\circ} \mathrm{C}$ immediately after the placenta was born.

\section{Analysis of DNA Methylation}

The deoxyribonucleosides 2'-deoxyguanosine (dG) monohydrate, 5-methyl-2`-deoxycytidine (5mdC) and 2'-deoxycytidine (dC) were purchased from ABCR (Karlsruhe, Germany). Hering sperm DNA was obtained from Sigma-Aldrich (Hamburg, Germany). Nuclease-free water for DNA extraction was purchased from Roth (Karlsruhe, Germany). LC-MS-grade water, methanol and formic acid were purchased from VWR international, Inc. (Dresden, Germany).

Preparation of stock solutions and calibration standards

Stock solutions of the standards were prepared by dissolving each analyte in LCMS-grade water at a concentration of $5 \mathrm{mM}$. All solutions were prepared freshly before analysis. The stock standard solutions were further diluted with water to yield the calibration standard concentrations of $0.05,0.1,0.5,1,2.5,5$ and $10 \%[5 \mathrm{mdC}] /[\mathrm{dG}]$ with $[\mathrm{dG}]$ being 20 pmol. Finally formic, acid was analyzed after adding formic acid with $0.1 \%(\mathrm{v} / \mathrm{v})$.

\section{DNA extraction and hydrolysis}

DNA was extracted using a QIAamp DNA Mini Kit from Qiagen (Hilden, Germany) together with an RNase A digestion according to the manufacturer`s protocol. The content and purity of the collected RNAfree DNA was assessed spectrophotometrically at 230, 260 and $280 \mathrm{~nm}$. Enzymatic DNA hydrolysis was performed using DNA Degradase Plus from Zymo Research (Freiburg, Germany). Briefly, $1 \mu \mathrm{g}$ of genomic DNA was mixed with $2.5 \mu \mathrm{L}$ 10X DNA Degradase Reaction Buffer, $1 \mu \mathrm{L}$ DNA Degradase Plus and filled up with water to a volume of $25 \mu \mathrm{L}$. After $4 \mathrm{~h}$ at $37^{\circ} \mathrm{C}$ the DNA digestion was stopped by adding $75 \mu \mathrm{L}$ of $0.1 \%$ formic acid. As a control $200 \mathrm{ng}$ of the digested DNA was analyzed by agarose gel electrophoresis. $70 \mu \mathrm{L}$ DNA hydrolysis samples were further diluted with $280 \mu \mathrm{L} 0.1 \%$ formic acid to yield a final concentration of $2 \mathrm{ng}$ digested DNA $/ \mu \mathrm{L}$.

\section{LC-ESI-MS/MS Procedure}

LC analysis was performed with an Agilent 1200 series HPLC system connected to an Agilent 6530 Accurate-Mass Q-TOF instrument with Jet Stream-Interface (Palo Alto, USA). For chromatographic separation a Waters (Milford, MA) X-Bridge ${ }^{\mathrm{TM}}$ C18 $4.6 \mathrm{~mm} \times 150 \mathrm{~mm}$ (3.5 $\mu$ m particle size) protected by a Waters X-Bridge ${ }^{\mathrm{TM}}$ C18 $4.6 \mathrm{~mm} \times 20 \mathrm{~mm}$ guard column (5 $\mu \mathrm{m}$ particle size) was used. $0.1 \%$ formic acid in water (solvent $\mathrm{A}$ ) and $0.1 \%$ formic acid in methanol (solvent $\mathrm{B}$ ) were chosen as mobile phases. The linear gradient elution was $4-20 \%$ of solvent B in $10 \mathrm{~min}$ at a constant flow rate of $0.5 \mathrm{~mL} / \mathrm{min}$. $50 \mu \mathrm{L}$ diluted DNA hydrolysis samples were injected, typically containing $100 \mathrm{ng}$ digested DNA. The optimized ESI-MS/ MS parameters in positive ion mode were as follows: gas temperature, $250{ }^{\circ} \mathrm{C}$; drying gas flow, $8 \mathrm{~L} / \mathrm{min}$; nebulizer pressure, $60 \mathrm{psig}$; sheat gas temperature, $300^{\circ} \mathrm{C}$; capillary voltage $4000 \mathrm{~V}$; collision energy $7 \mathrm{~V}$ for $\mathrm{dC}, 13 \mathrm{~V}$ for $5 \mathrm{mdC}$ and $10 \mathrm{~V}$ for $\mathrm{dG}$. Quantification was accomplished in multiple reaction monitoring (MRM) mode by monitoring a transition pair of $m / z$ 228.0979/112.0505 for dC, $m / z$ 242.1135/126.0662 for $5 \mathrm{mdC}$ and $m / z$ 268.1040/152.0780 for $\mathrm{dG}$, which was used as an internal standard for the measurement. The scan time was $333 \mathrm{~ms}$ for each pair.

\section{Percentage of methylation}

The percentage of methylation was calculated as: Methylation $\%=[5 \mathrm{mdC}] /[\mathrm{dG}]$ according to the calibration curve. 


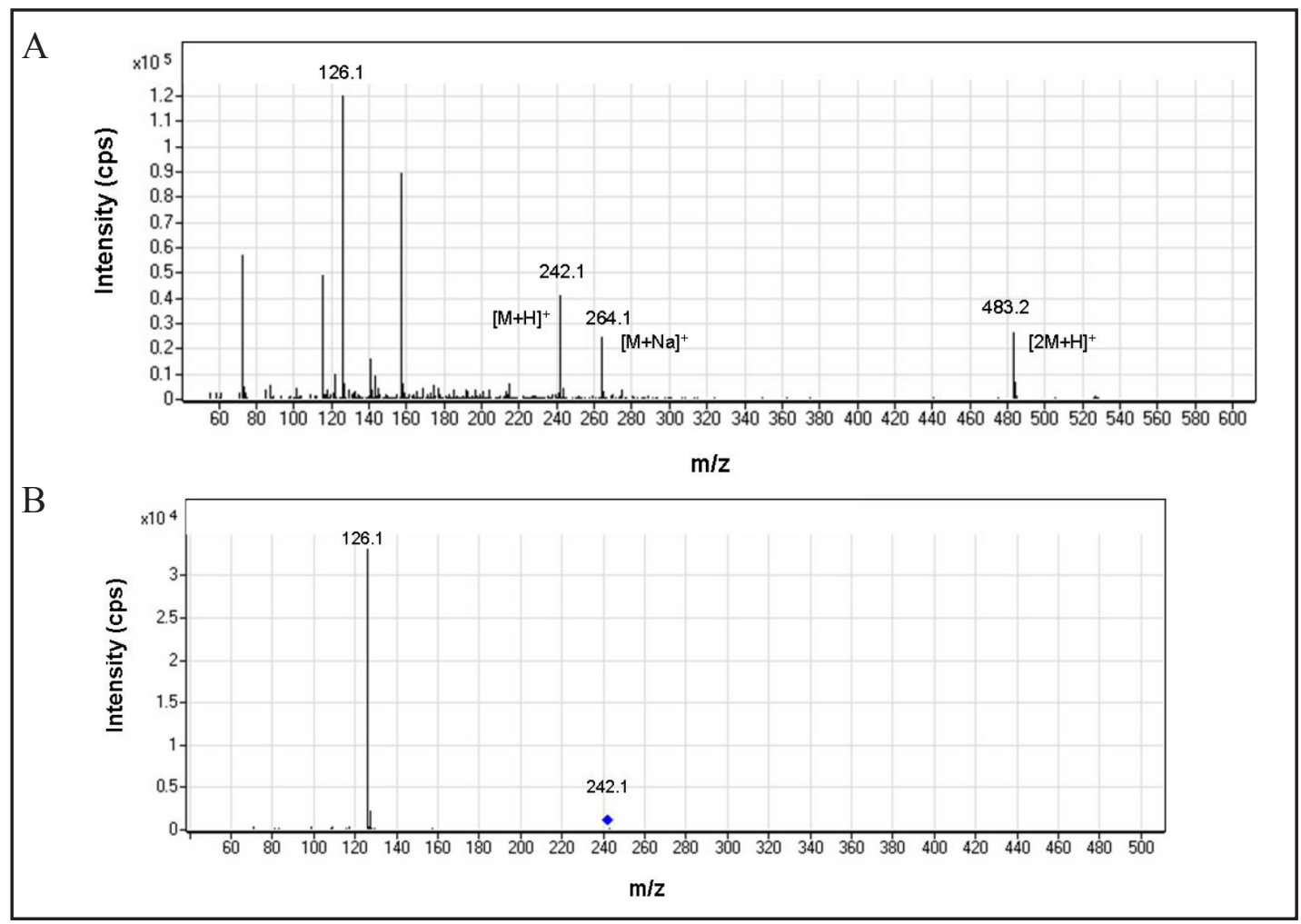

Fig. 1. A: Full-scan spectrum (ESI-MS-spectrum) of a standard solution of $5 \mathrm{mdC}$. Only one protonated $[\mathrm{M}+\mathrm{H}]+$ adduct of $5 \mathrm{mdC}$ is detectable at $\mathrm{m} / \mathrm{z} 242.1135$. $\mathrm{B}:$ A product ion spectrum of $5 \mathrm{mdC}(\mathrm{m} / \mathrm{z} 242.1135)$ can be found after the fragmentation, when the main $[\mathrm{M}+\mathrm{H}]+$ adduct of $5 \mathrm{mdC}$ appearsat $\mathrm{m} / \mathrm{z} 126.0662$.

\section{Results and Discussion}

\section{Method development and validation}

Optimization of HPLC-ESI-MS/MS conditions

Figure 1A shows the full-scan spectrum (ESI-MS-spectrum) of a standard solution of $5 \mathrm{mdC}$. With the optimized ESI-conditions only one protonated $[\mathrm{M}+\mathrm{H}]^{+}$adduct of $5 \mathrm{mdC}$ is detectable at $m / z$ 242.1135. No $[\mathrm{M}+\mathrm{Na}]^{+}$but an $[2 \mathrm{M}+\mathrm{H}]^{+}$adduct occurred, having a sensitivity less than $3 \%$ of the main adduct. Figure $1 \mathrm{~B}$ reports the product ion spectrum of $5 \mathrm{mdC}(\mathrm{m} / \mathrm{z}$ $242.1135)$. It can be found after the fragmentation, when the main $[\mathrm{M}+\mathrm{H}]^{+}$adduct of $5 \mathrm{mdC}$ appears at $m / z 126.0662$. This ion originates due to the cleavage of the $N$-glycoside bond and transfer of a hydrogen atom from the sugar molecule [24]. Because these findings are comparable to the detection of $\mathrm{dC}$ and $\mathrm{dG}$, the precursor/product ion pairs of $\mathrm{m} / \mathrm{z}$ 228.0979/112.0505 for $\mathrm{dC}, \mathrm{m} / z$ 242.1135/126.0662 for $5 \mathrm{mdC}$ and $m / z$ 268.1040/152.0780 for $\mathrm{dG}$ were used as MRM transitions.

For high-sensitivity ESI-MS/MS measurements the ESI conditions were first optimized for the $[\mathrm{M}+\mathrm{H}]^{+}$adduct of $5 \mathrm{mdC}$, as shown in Figure $1 \mathrm{~A}$.

\section{RNA contamination}

Interference from RNA contamination poses a potential problem in the analysis of genomic DNA methylation [20]. In order to prevent those interferences, a sufficient DNA purification procedure with removal of RNA was chosen. In addition, an optimized gradient elution program with $0.1 \%$ formic acid in water and $0.1 \%$ formic acid in methanol was used to separate uracil and $5 \mathrm{dmC}$, which typically elute at the same time. Figure 2 illustrates no interference of $5 \mathrm{mdC}$ with uracil. 
Fig. 2. A gradient elution program with $0.1 \%$ formic acid in water and $0.1 \%$ formic acid in methanol was used to separate uracil and $5 \mathrm{dmC}$, which elute at the same time. There were no interference of $5 \mathrm{mdC}$ with uracil.

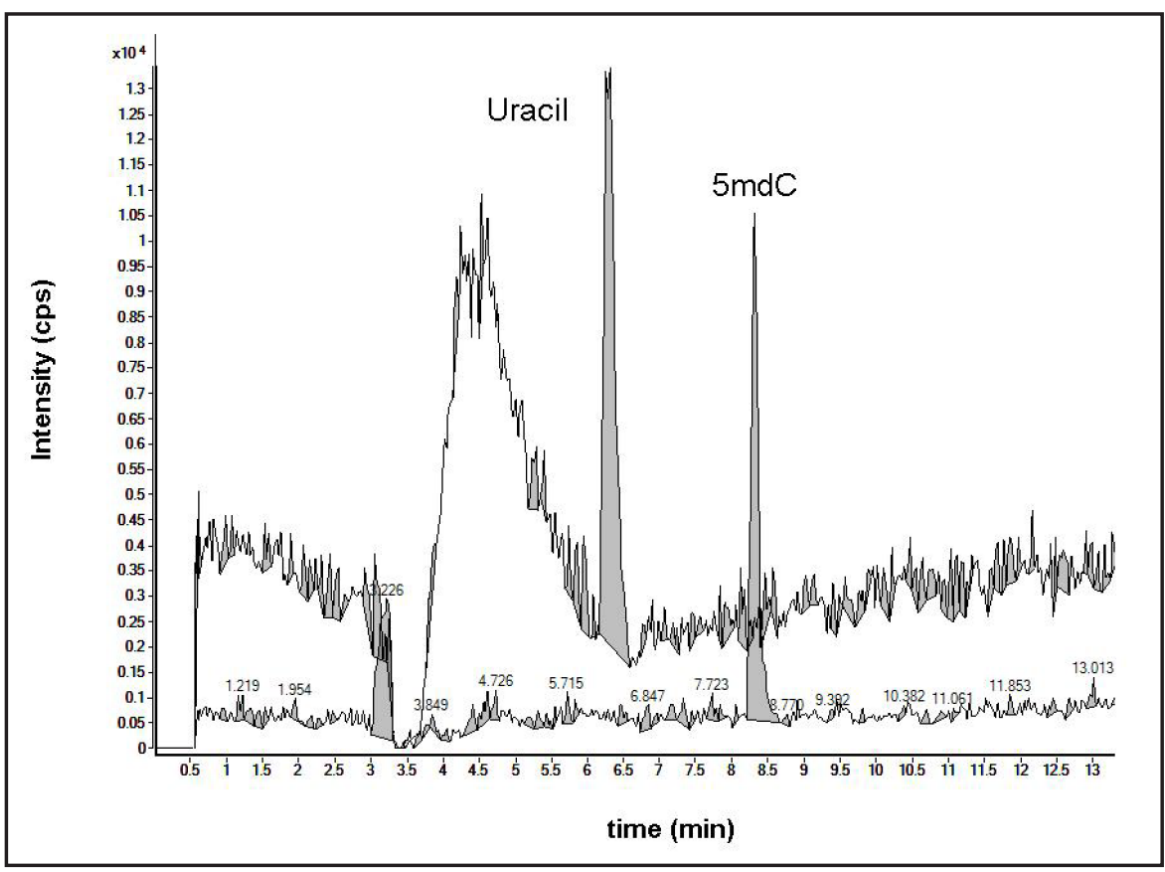

Fig. 3. Typical calibration curve of $5 \mathrm{mdC}$. The limit of detection (LOD) of $5 \mathrm{mdC}(\mathrm{S} / \mathrm{N}=3)$ was determined to be $10 \mathrm{fmol}$. The limit of quantification (LOQ) of $5 \mathrm{mdC}(\mathrm{S} / \mathrm{N}=10)$ was found to be $50 \mathrm{fmol}$.

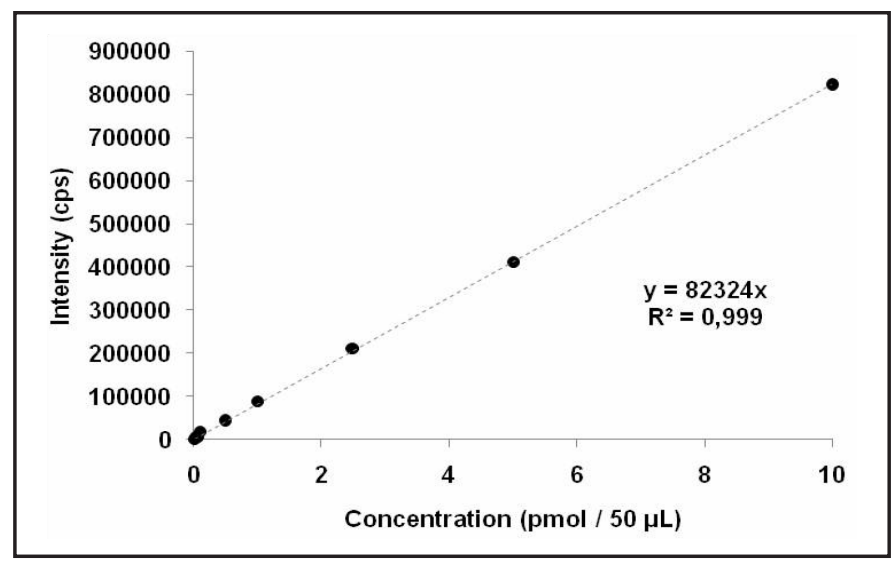

Calibration curves and sensitivity

Figure 3 shows a typical calibration curve of $5 \mathrm{mdC}$. The limit of detection (LOD) of $5 \mathrm{mdC}(\mathrm{S} / \mathrm{N}=3)$ was determined to be $10 \mathrm{fmol}$. The limit of quantification (LOQ) of $5 \mathrm{mdC}$ $(\mathrm{S} / \mathrm{N}=10)$ was found to be $50 \mathrm{fmol}$.

\section{Calculation of genomic DNA methylation}

Using an isotope labeled internal standard is one of the most accurate measurements of the methylation level in genomic DNA [25]. But it would get lost during sample preparation, where spin columns are used, which only adsorbs whole DNA molecules. Therefore usually, the global level of methylation is calculated as $[5 \mathrm{mdC}] /([5 \mathrm{mdC}]+[\mathrm{dC}])$ using $\mathrm{dC}$ as internal standard. Since many modifications of $\mathrm{dC}$ are described, we decided to use the more stable $d G$ instead, based on the assumption that in genomic DNA $[\mathrm{dG}]=[5 \mathrm{mdC}]+[\mathrm{dC}][20]$. We calculated the grade of methylation in DNA as $[5 \mathrm{mdC}] /[\mathrm{dG}]$ and injected $100 \mathrm{ng}$ of digested DNA, which conforms to $\sim 20 \mathrm{pmol} d \mathrm{~d}$. For this reason calibration curves were prepared to imitate DNA hydrolysis products with 20 pmol of dG, $\mathrm{dC}$ and $0.5,1,2.5,5$ and $10 \%$ [5mdC]/ [dG], as typically $2-6 \%$ of the mammalian DNA is methylated [26]. Figure 4 shows a LC-ESI$\mathrm{MS} / \mathrm{MS}$ chromatogram of a calibration mixture containing $20 \mathrm{pmol} \mathrm{dG}, \mathrm{dC}$ and $2.5 \%$ [ $5 \mathrm{mdC}] /$ [dG]. 


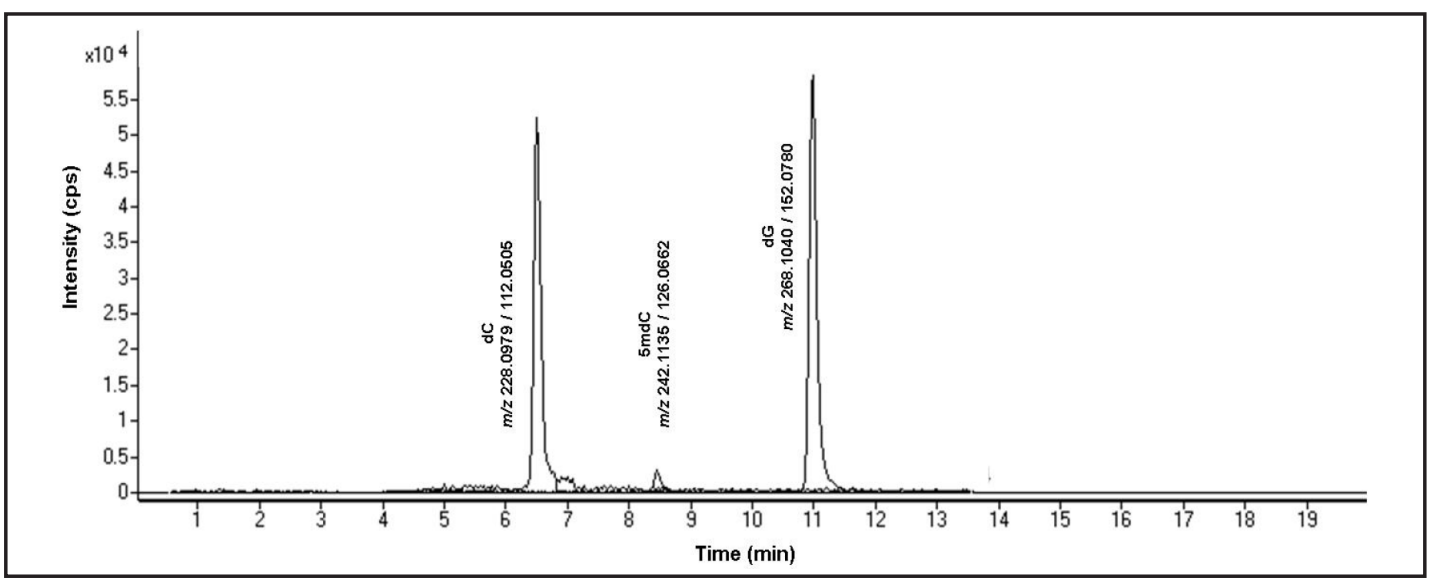

Fig. 4. LC-ESI-MS/MS chromatogram of a calibration mixture containing $20 \mathrm{pmol} \mathrm{dG}$, dC and 2.5\% [5mdC]/ [dG].

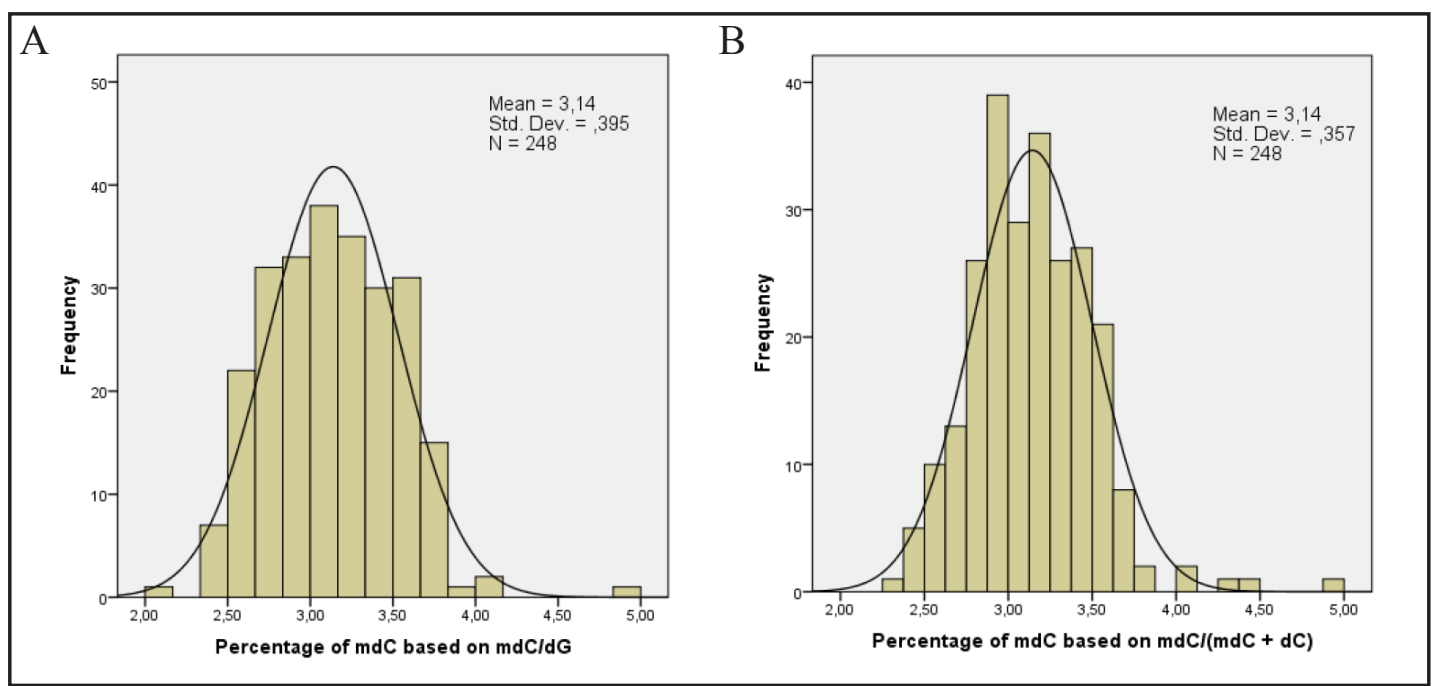

Fig. 5. A: Histogram showing the distribution of $\% \mathrm{mdC}$ based on $\mathrm{mdC} / \mathrm{dG}$. B: Histogram showing the distribution of $\% \mathrm{mdC}$ based on $\mathrm{mdC} /(\mathrm{mdC}+\mathrm{dC})$.

Table 1. Intra-day precision of the LC-ESIMS/MS method for the analysis of genomic DNA methylation levels. a Relative standard deviation, b relative error

\begin{tabular}{lc}
\hline & Human placenta DNA \\
$\mathrm{n}$ & 4 \\
\hline Calculated mean $[5 \mathrm{mdC}] /[\mathrm{dG}](\%)$ & 4.21 \\
$\mathrm{RSD}(\%)^{\mathrm{a}}$ & 0.06 \\
$\mathrm{RE}(\%)^{\mathrm{b}}$ & 0.03 \\
\hline
\end{tabular}

Table 2. Robustness of the LC-ESI-MS/MS method for the analysis of genomic DNA methylation levels. a Relative standard deviation, b relative error

\begin{tabular}{lccc}
\hline & Human placenta DNA & Hering sperm DNA & HeLa DNA \\
$\mathrm{n}$ & 6 & 3 & 3 \\
\hline Calculated mean & & & \\
{$[5 \mathrm{mdC}] /[\mathrm{dG}](\%)$} & 4.27 & 2.63 & 7.10 \\
RSD $(\%)^{\mathrm{a}}$ & 0.16 & 0.23 & 0.26 \\
$\mathrm{RE}(\%)^{\mathrm{b}}$ & 0.06 & 0.13 & 0.15 \\
\hline
\end{tabular}

\section{Accuracy, intra-day precision and robustness}

Accuracy, intra-day precision and robustness of the LC-ESI-MS/MS method were assessed by measuring calibration curves and herring sperm DNA on five different days. Intra-day precision was determined by repeated analysis of standard curves at different 
times during the same day $(n=2)$. Robustness was evaluated by repeated measurements of standard curves and hering sperm DNA on five different days. All in all, the method illustrates a very consistent and reliable method with overall low relative standard deviations (RSDs) and relative errors (REs) (Tables 1 and 2). The time interval between two different sample injections was 20 minutes. As the actual sample measurement is an automated process, this method is suitable for large sample sizes.

\title{
Clinical data
}

The results of the analysis of 248 placenta samples from the BBC study cohort [21$23]$ are shown in Fgure 5A. The degree of DNA methylation ranges from $2 \%$ to $5 \%$. This high variability of DNA methylation is remarkable given the fact that this tissue is just 9 months old. Epigenetic alterations are thought to be acquired upon environmental challenges. This may indicate that differences in environmental toxic and/or nutritional exposure of pregnant women translated into epigenetic modulation of the overall placenta DNA methylation degree. If DNA methylation is present in promoters of genes that control key placenta function, differences in DNA methylation should result in differences in the offspring`s phenotype. This should be addressed in future larger studies being adequately powered for such questions. In any case, it is important to note that the degree of placental DNA methylation varies substancially although the age of the tissue is just 9 months. Two ways of calculating the methylation degree are shown in Figure 5A and 5B. We suggest calculating the degree of DNA methylation as $\mathrm{dmC} / \mathrm{dG}$, because many modifications of $\mathrm{dC}$ are described and $\mathrm{dG}$ is more stable. This is justified by the assumption that in genomic DNA $[\mathrm{dG}]=[5 \mathrm{mdC}]+[\mathrm{dC}][20]$.

\section{Conclusions}

In conclusion, High Performance Liquid Chromatography- Electrospray Tandem Mass Spectrometry (HPLC-ESI-MS/MS) based quantification of the $\mathrm{dmC} / \mathrm{dG}$ ratio is a reliable, stable method to determine global DNA methylation in large clinical trials. The degree of DNA methylation varies substantially in the human placenta. The clinical implications need to be demonstrated in adequately powered studies. Environmental challenges in early life seem to affect multiple (hundreds) of genes. This explains why we could detect such differences in global DNA methylation in our cohort. It is unclear so far whether the pattern of global DNA methylation is different upon different environmental stimuli. We believe that this might be the case, since different environmental stimuli cause different phenotypes in the offspring (1-3). Studies in the future need to test this hypothesis. We suggest that the method described here is a suitable screening method to decide whether or not an environmental challenge in early life may cause fetal programming. If this is the case, not yet existing methods needs to be applied to describe the most likely very complex patterns of DNA methylation.

\section{References}

\author{
Barker DJP: The developmental origins of adult disease. J Am Coll Nutr 2004;23:588S-595S. \\ Nakao M: Epigenetics: interaction of DNA methylation and chromatin. Gene 2001;278:25-31. \\ Skinner MK: Role of epigenetics in developmental biology and transgenerational inheritance. Birth Defects \\ Research Part C: Embryo Today: Reviews 2011;93:51-55. \\ 4 Koukoura O, Sifakis S, Spandidos DA: DNA methylation in the human placenta and fetal growth (review). \\ Mol Med Rep 2012;5:883-889. \\ -5 Fowden AL, Forhead AJ: Endocrine interactions in the control of fetal growth. Nestle Nutr Inst Workshop \\ Ser 2013;74:91-102. \\ 6 Hemberger M: Genetic-epigenetic intersection in trophoblast differentiation: implications for \\ extraembryonic tissue function. Epigenetics 2010;5:24-29.
}


Putra et al.: DNA Methylation Levels in Human Placenta

7 Feng S, Jacobsen SE, Reik W: Epigenetic reprogramming in plant and animal development. Science 2010;330:622-627.

8 Gheorghe CP, Goyal R, Mittal A, Longo LD: Gene expression in the placenta: maternal stress and epigenetic responses. Int J Dev Biol 2010;54:507-523.

-9 Nomura Y, Lambertini L, Rialdi A, Lee M, Mystal EY, Grabie M, Manaster I, Huynh N, Finik J, Davey M, Davey K, Ly J, Stone J, Loudon H, Eglinton G, Hurd Y, Newcorn JH, Chen J: Global methylation in the placenta and umbilical cord blood from pregnancies with maternal gestational diabetes, preeclampsia, and obesity. Reprod Sci 2014;21:131-137.

-10 Janssen BG, Godderis L, Pieters N, Poels K, Kici Ski M, Cuypers A, Fierens F, Penders J, Plusquin M, Gyselaers W, Nawrot TS: Placental DNA hypomethylation in association with particulate air pollution in early life. Part Fibre Toxicol 2013;10:22.

11 Gallou-Kabani C, Gabory A, Tost J, Karimi M, Mayeur S, Lesage J, Boudadi E, Gross MS, Taurelle J, Vigé A, Breton C, Reusens B, Remacle C, Vieau D, Ekström TJ, Jais JP, Junien C: Sex- and Diet-Specific Changes of Imprinted Gene Expression and DNA Methylation in Mouse Placenta under a High-Fat Diet. PLoS One 2010;5. DOI: 10.1371/journal.pone.0014398

12 Filiberto AC, Maccani MA, Koestler D, Wilhelm-Benartzi C, Avissar-Whiting M, Banister CE, Gagne LA, Marsit CJ: Birthweight is associated with DNA promoter methylation of the glucocorticoid receptor in human placenta. Epigenetics 2011;6:566-572.

13 Gluckman PD, Hanson MA: Developmental and epigenetic pathways to obesity: an evolutionarydevelopmental perspective. Int J Obes (Lond) 2008;32:S62-71.

14 Nafee TM, Farrell WE, Carroll WD, Fryer AA, Ismail KMK: Epigenetic control of fetal gene expression. BJOG 2008;115:158-168.

15 Strachan T: Human molecular genetics 3. 3rd ed New York, London, Garland Science, 2004.

16 Trasler JM: Gamete imprinting: setting epigenetic patterns for the next generation. Reprod Fertil Dev 2006;18:63-69.

17 Bird A: DNA methylation patterns and epigenetic memory. Genes Dev 2002;16:6-21.

18 Jaenisch R, Bird A: Epigenetic regulation of gene expression: how the genome integrates intrinsic and environmental signals. Nat Genet 2003;33:S245-254.

19 Venhoranta H, Li S, Salamon S, Flisikowska T, Andersson M, Switonski M, Kind A, Schnieke A, Flisikowski $\mathrm{K}$ : Non-CpG hypermethylation in placenta of mutation-induced intrauterine growth restricted bovine foetuses. Biochem Biophys Res Commun 2014; DOI: 10.1016/j.bbrc.2014.01.071

-20 Song L, James SR, Kazim L, Karpf AR: Specific method for the determination of genomic DNA methylation by liquid chromatography-electrospray ionization tandem mass spectrometry. Anal Chem 2005;77:504510.

-21 Hocher B, Slowinski T, Stolze T, Pleschka A, Neumayer HH, Halle H: Association of maternal G protein [beta] 3 subunit 825T allele with low birthweight. The Lancet 2000;355:1241-1242.

22 Pfab T, Slowinski T, Godes M, Halle H, Priem F, Hocher B: Low birth weight, a risk factor for cardiovascular diseases in later life, is already associated with elevated fetal glycosylated hemoglobin at birth. Circulation 2006;114:1687-1692.

23 Nair AV, Hocher B, Verkaart S, van Zeeland F, Pfab T, Slowinski T, Chen YP, Schlingmann KP, Schaller A, Gallati S, Bindels RJ, Konrad M, Hoenderop JG: Loss of insulin-induced activation of TRPM6 magnesium channels results in impaired glucose tolerance during pregnancy. Proc Natl Acad Sci USA 2012;109:1132411329.

24 Hu J, Zhang W, Ma H, Cai Y, Sheng G, Fu J: Simultaneous determination of 8-hydroxy-2'-deoxyguanosine and 5-methyl-2'-deoxycytidine in DNA sample by high performance liquid chromatography/positive electrospray ionization tandem mass spectrometry. J Chromatogr B Analyt Technol Biomed Life Sci 2010;878:2765-2769.

25 Friso S, Choi S-W, Dolnikowski GG, Selhub J: A method to assess genomic DNA methylation using high-performance liquid chromatography/electrospray ionization mass spectrometry. Anal Chem 2002;74:4526-4531.

-26 Kyoung Kim H, Kyoung Kim Y, Song IH, Baek SH, Lee SR, Hye Kim J, Kim JR: Down-Regulation of a Forkhead Transcription Factor, FOXO3a, Accelerates Cellular Senescence in Human Dermal Fibroblasts. J Gerontol A Biol Sci Med Sci 2005;60:4-9. 